\title{
La importancia de los tanques naturales (mega gnammas) en la preservación de fósiles de la Megafauna cuaternaria en el Noreste de Brasil
}

\author{
Importance of natural tanks (mega gnammas) \\ in the preservation of fossils of the Quaternary \\ Megafauna in the Northeast of Brazil
}

\begin{abstract}
RODRIGUES WALDHERR, F. ${ }^{1}$, ISMAEL DE ARAÚJO-JÚNIOR, H. ${ }^{2}$, WILIANS DE OLIVEIRA RODRIGUES, S. ${ }^{3} \&$ LIRA XIMENES, C. ${ }^{4}$

${ }^{1}$ Programa de Pós-graduação em Geografia, Departamento de Geografia, Universidade Federal do Rio de Janeiro. Av. Athos da Silveira Ramos, 274, Cidade Universitária, CEP 21941-916, Rio de Janeiro, RJ, Brasil. E-mail: felipewald@gmail.com

${ }^{2}$ Departamento de Estratigrafia e Paleontologia, Faculdade de Geologia, Universidade do Estado do Rio de Janeiro. Rua São Francisco Xavier, 524, Maracanã, CEP 20550-013, Rio de Janeiro, RJ, Brasil. E-mail: herminio.ismael@yahoo.com.br

${ }^{3}$ Departamento de Geologia, Instituto de Ciências e Tecnologia, Universidade Federal de Goiás. Rua Mucuri, s/n, Parque Itatiaia, CEP 74968-755, Aparecida de Goiânia, GO, Brasil. E-mail: swor@ufg.br ${ }^{4}$ Museu de Pré-História de Itapipoca (MUPHI), Rua Dom Aureliano Matos, 224, Praça Perilo Teixeira, Centro, CEP 62500-004, Itapipoca, CE, Brasil. E-mail: clx.ximenes@gmail.com
\end{abstract}

https://doi.org/10.17979/cadlaxe.2019.41.0.5819 enviado: 2/2/2019 aceptado 23/7/2019

\footnotetext{
Abstract:

Tanks (mega gnammas) of natural origin excavated in rock constitute medium-sized forms very frequent in the granite reliefs of Northeast Brazil. The study of the accumulated
} 
sediments inside these natural tanks has become a source of data of great interest for the knowledge of the quaternary paleontology of Brazil. This type of cavity in areas of granite substrate, once exposed on the surface have acted as local depocenters for water flows and associated sediments, sometimes fossiliferous, which has turned these hollows into true thanatocoenoses. The systematic study of the fossiliferous accumulations has become the main tool to reconstruct the paleoenvironmental and paleoecological conditions during part of the Quaternary period in the Brazilian Intertropical Region.

Key-words: Natural tanks, Meso forms, Granite geomorphology, Quaternary, Brazilian Northeast.

\section{Resumen:}

Los tanques (mega gnammas) de origen natural excavados en roca constituyen formas de tamaño medio muy frecuentes en los relieves graníticos del Noreste de Brasil. El estudio de los sedimentos acumulados en el interior de esos tanques naturales se ha convertido en una fuente de datos de gran interés para el conocimiento de la paleontología cuaternaria de Brasil. Este tipo de cavidades habituales en zonas de sustrato granítico, una vez expuestas en superficie han actuado como depocentros locales para los flujos de agua y sus sedimentos asociados, a veces fosilíferos, lo que ha convertido estas concavidades en auténticas tanatocenosis. El estudio sistemático de las acumulaciones fosilíferas se ha convertido así en la principal herramienta para reconstruir las condiciones paleoambientales y paleoecológicas durante parte del período Cuaternario en la Región Intertropical Brasileña.

Palabras-clave: Tanques naturales, Formas medias, Geomorfología granítica, Cuaternario, Noreste brasileño. 


\section{INTRODUCCIÓN}

Las primeras referencias a tanques naturales (mega gnammas) y los depósitos fosilíferos asociados a ellas en el Noreste de Brasil se remontan a finales del siglo XVIII (XIMENES, 2006a; FERNANDES et al., 2013a) e inicios del siglo XIX (CASAL, 1817 a y b; HENDERSON, 1821; GRAHAM, 1824; SPIX \& MARTIUS, 1824, 1828). Las expediciones científicas de naturalistas que recorrieron el noreste brasileño, durante los siglos XIX y XX, utilizaron el término tanque (lato sensu) para denominar estas depresiones naturales en zonas de sustrato rocoso granítico, asociadas a las que se han encontrado numerosos yacimientos fosilíferos de edad pleistocena (BURLAMAQUE, 1855, 1856; KRATIF, 1858; CAPANEMA, 1866; HARTT, 1870; BRANNER, 1902, 1915; MORAES, 1924, 1928). Actualmente se usa el mismo término (tanques) para referirse, de forma generalizada, tanto a concavidades naturales desarrolladas en el substrato granítico-gnéisico como, ocasionalmente, sobre rocas sedimentarias del Nordeste de Brasil (MABESOONE et al., 1990; SANTOS et al., 2002; XIMENES, 2003, 2009; ARAÚJO-JÚNIOR \& PORPINO, 2011; ARAÚJO-JÚNIOR et al., 2011, 2013a, 2013b, 2015, 2016; LIMA et al., 2013; LIMA \& SILVA, 2016).

Aunque el término tanque (lato sensu) se reserva de manera habitual en los trabajos paleontológicos para este tipo de formas menores y medias en relieves graníticognéisicos, no existe todavía consenso o un estudio sistemático sobre los diferentes tipos de cavidades y en especial para explicar su génesis y origen. Esto ha dado lugar a una gran variedad de interpretaciones así como una variada nomenclatura que es empleada, igeneralizadamente, en el Noreste de Brasil (por ejemplo: cacimba, caldeirão, marmita, oriçanga, panela, buraco, bacia de dissolução y depressão de intemperismo). WALDHERR et al. (2017a, 2017b, 2018) basándose en ideas previas sobre la génesis de rocas graníticas (TWIDALE \& VIDAL ROMANÍ, 2005 y más especialmente VIDAL ROMANÍ, (2008), las han adaptado al caso brasileño desarrollando una clasificación de procesos responsables del origen y morfología de estas cavidades naturales situadas en el Noreste y Sureste de Brasil. El término "tanque natural" (stricto sensu) o macro gnamma se refiere por tanto a cavidades naturales (de origen no fluvial) debidas o bien a procesos de corrosión química o, con mayor verosimilitud, a procesos de origen tectónico desarrollados durante la etapa intrusiva del granito (VIDAL ROMANÍ, 2008). Durante esta tiene lugar la formación de volúmenes de deterioro físico en la roca producidos por migración y concentración de cargas. en zonas localizadas del granito, relacionadas con la sheet structure o en cualquier caso con la superficie de diaclasas ofracturas. Estas zonas son así puntos de debilidad del sustrato rocoso y una vez alcanzadas condiciones subedáficas son alteradas (VIDAL ROMANÍ, 2008) y la roca afectada evacuada, dejando la cavidad libre en superficie hasta que, posteriormente, ses rellenada por los sedimentos fosilíferos. Los términos "marmitas" o "caldeirões" se utilizarían para designar otro tipo de cavidades naturales (formas fluviales) debidas a procesos de evorsión y/o cavitación, o sea, de un tipo de abrasión provocado por movimiento turbillonar sobre el lecho rocoso de los ríos. Es por esta razón que las cavidades asociadas al término marmitas tienen características morfológicas muy distintas a los que presentan, los llamados aquí tan- 
ques naturales. Según los autores brasileños, los tanques naturais (stricto sensu) pueden ser subdivididos en "tanque natural raso" o "tanque natural escarpado" (en idioma español: tanque natural "somero" y tanque natural "profundo"), teniendo en cuenta los procesos genéticos involucrados, la morfología de la cavidad y su forma expuesta al basamento cristalino (WALDHERR et al. 2017a, 2017b, 2018).

Ya analizando el tema de este trabajo con otra perspectiva, las cavidades desarrolladas sobre el sustrato granítico una vez expuestas en superficie se transforman en puntos de coalescencia de flujos y de los materiales arrastrados, convirtiéndose, aunque a pequeña escala, en auténticas tanatocenosis. Los depósitos sedimentarios confinados en los tanques naturais (stricto sensu) han proporcionado desde el siglo XVIII información y datos paleoambientales sobre el período Cuaternario en el extremo septentrional del continente sudamericano. De manera general los tanques y sus depósitos sedimentarios constituyeron también un importante hito para la consolidación de los estudios paleontológicos en Brasil.

Este trabajo trata de aportar información sobre las recientes investigaciones relacionadas con los tanques naturales en Brasil y presenta un registro histórico de estos importantes rasgos geomorfológicos, así como de su relevancia para la Paleontología, debido a la preservación en ellos de registros fosilíferos del Pleistoceno Final. De este modo, la finalidad de este trabajo es suplir la ausencia existente sobre el conocimiento e importancia de los tanques naturales, además, constituye una posible contribución al estudio de este tipo de formas específicas que se encuentran sobre el basamento granítico-gnéisico del Noreste de Brasil.

\section{Ubicación Geográfica}

Los tanques naturales y sus depósitos fosilíferos asociados, se localizan en parte de la región del Noreste de Brasil, más precisamente los Estados de Ceará, Rio Grande do Norte, Paraíba, Pernambuco, Alagoas, Sergipe y la parte norte del Estado de Bahia (Figura 1). Desde un punto de vista geomorfológico los denominados tanques naturais (stricto sensu) constituyen casos singulares de formas menores y medias en el relieve granítico-gnéisico del Noreste de Brasil. La situación de estas cavidades naturales corresponde a los compartimientos geomorfológicos denominados "Depressão Sertaneja" y "Planalto da Borborema" (OLIVEIRA \& HACKSPACHER, 1989; BERQGVIST et al., 1997; BARRETO et al., 2004; XIMENES, 2003, 2009; SILVA et al., 2017; WALDHERR et al., 2017a, MAIA \& NASCIMENTO, 2018). La primera o "Depressão Sertaneja" es una depresión de gran extensión que varía topográficamente de plana a suavemente ondulada, constituyendo superficies con altitudes entre 50 y 300 metros, interrumpida de manera ocasional por relieves residuales, inselbergs y bornhardts (MAIA \& BEZERRA, 2014). Por lo que se refiere a la segunda unidad geomorfológica o "Planalto da Borborema" está formado por sierras y superficies aplanadas que se ubican en el interior del continente a elevaciones que superan los 650 metros (ver CORRÊA et al., 2010). Generalmente los tanques naturales se ubican cerca de macizos rocosos, o asociados a lajas de exfoliación o, ocasionalmente, con los llamados regionalmente mares de piedras o bloques (caos de bloques). Sin embargo, en un reciente relevamiento en terreno se registró el primer hallazgo de tanques naturales con depósitos sedimentarios 


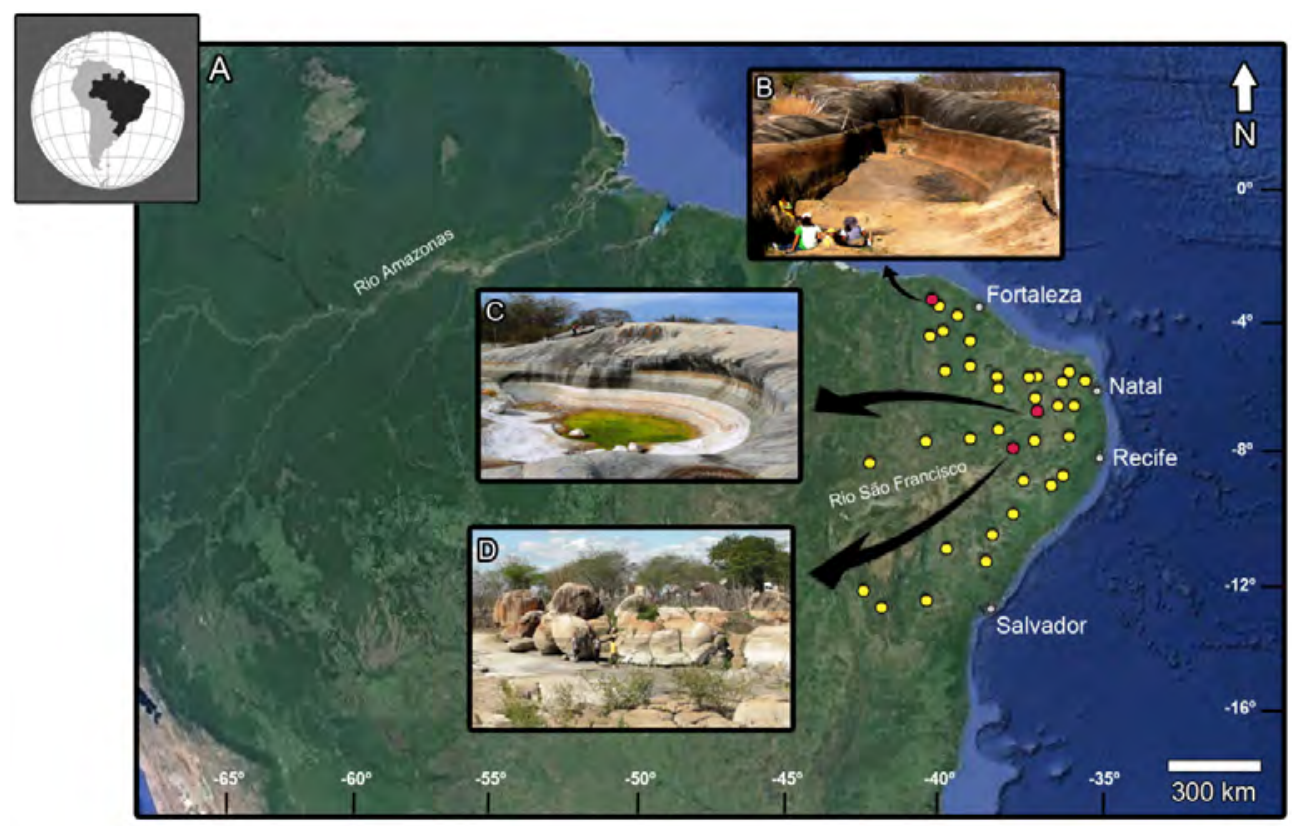

Fig. 1. Mapa de la distribución geográfica de los tanques (lato sensu) fosilíferos estudiados en la región Noreste de Brasil. A) Los puntos amarillos representan depósitos de tanques evaluados en trabajos previos sobre términos taxonómicos, tafonómicos o paleoecológicos; los puntos rojos son tanques representados en B-D; B) Tanque de Jirau, ubicado en el Sitio Paleontológico de Jirau, Itapipoca, Estado de Ceará; C) Tanque ubicado en el Sitio Paleontológico de Curimatãs, Pocinhos, Estado de Paraíba; D) Tanque ubicado en el Sitio Paleontológico de Lage Grande, Alagoinha, Estado de Pernambuco. Escalas en B-D: Escala humana. Fuente: Google Earth (modificado de ARAÚJO-JÚNIOR, 2016; WALDHERR et al., 2017a).

asociados en el Sureste de Brasil (WALDHERR et al., 2017b; WALDHERR, 2018).

\section{Basamento Geológico}

El basamento geológico del área de estudio ocupa por completo la Provincia Estructural Borborema y la parte septentrional del Cráton de São Francisco (Figura 2). Según ALMEIDA et al. (1981), la Provincia Borborema comprende un área del Noreste septentrional ubicada al este de la Cuenca Sedimentaria del Parnaíba y al norte del Cratón de São Francisco. RODRIGUES et al. (2010) definen la Pro- vincia como una amplia región brasileña constituida por litologías metamórficas e ígneas, formada por un sistema ramificado de orógenos neoproterozoicos, separados por terrenos de edad proterozoica donde, eventualmente, se distinguen núcleos del Arcaico (ALMEIDA et al., 1981; BRITO NEVES et al. 2000). Los autores destacan además la complejidad estratigráfica y geocronológica del área que define una serie de compartimentos tectónicos caracterizados por diferentes aspectos geológicos y geofísicos (RODRIGUES et al., 2010). El Cráton de São Francisco está constituido por un bloque del Arcaico que sobrevivió a 
las orogénesis del Proterozoico, y por fragmentos de un orógeno paleoproterozoico, desarrollado durante el acontecimiento Transamazónico, alrededor de 2,1 Ga (ALKMIM, 2004). Según TEIXEIRA et al. (2000), el basamento cristalino del Cráton de São Francisco está formado por una compleja disposición de terrenos de alto grado metamórfico, constituidos por gneisses, granitoides y granulitas de edad arcaica, conjuntos del tipo granito greenstone y franjas móviles de rocas supracorticales paleoproterozoicas. En la parte noreste del Cráton de São Francisco se encuentran afloramientos de rocas plutónicas con una gran variedad composicional.

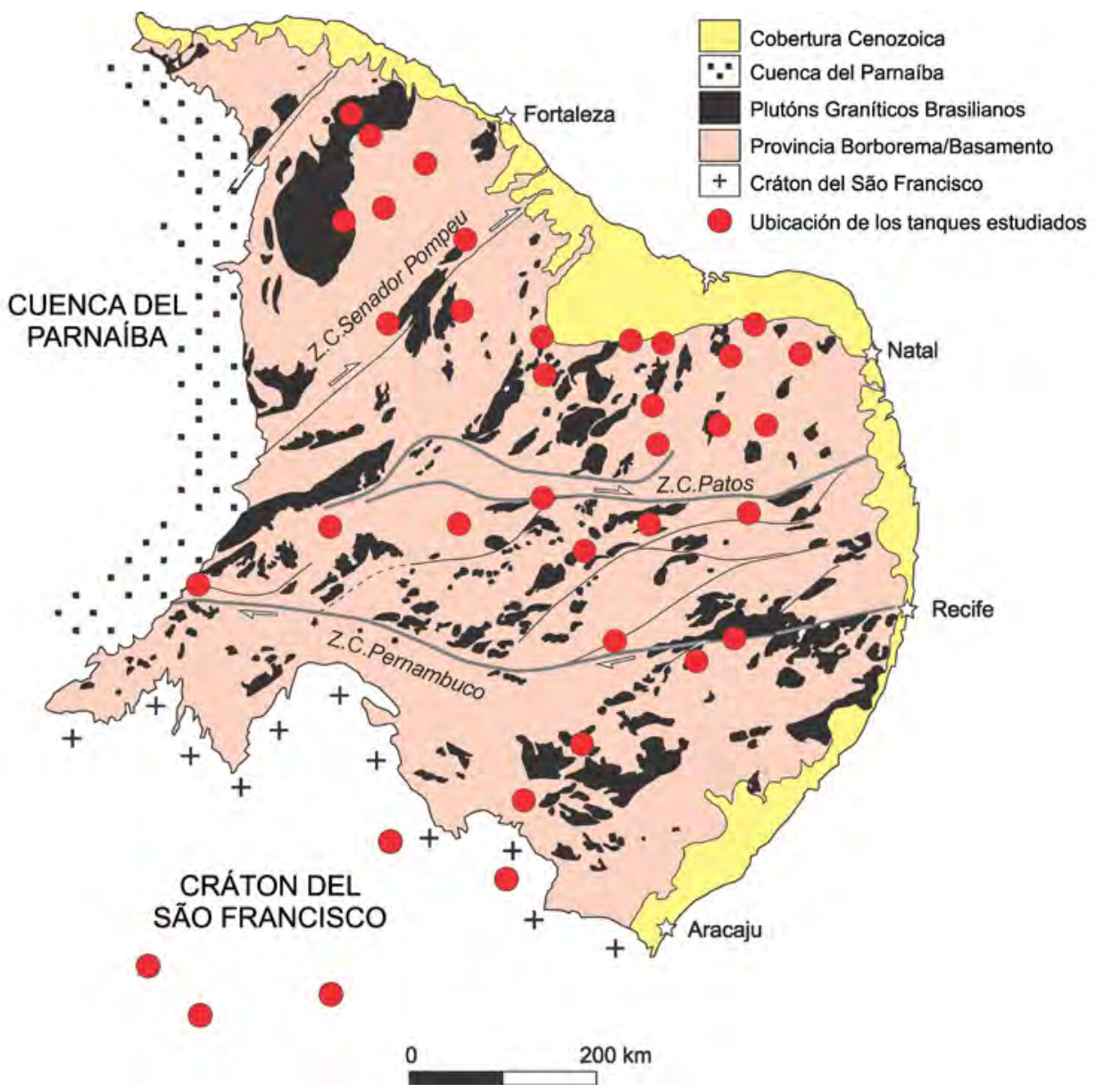

Fig. 2. La Provincia Borborema (Noreste de Brasil) destacando la ubicación de los tanques (lato sensu) con contenido fosilífero mencionados en este trabajo junto con la distribución de los macizos de rocas plutónicas del Brasiliano-Pan Africano y su relación con las zonas de cizallamiento (líneas contínuas en negro) (modificado de ARCHANJO et al., 2008; WALDHERR et al., 2017a). 


\section{Los tanques naturales y depósitos} sedimentarios

En el Noreste de Brasil la mayoría de los tanques naturales (stricto sensu) se presentan con formas ovaladas, elípticas y/o circulares (XIMENES, 2003, 2009; WALDHERR et al., 2017a; MAIA \& NASCIMENTO, 2018; MAIA et al., 2018). En algunos casos las cavidades naturales tienen paredes internas con contornos angulares, lo que prueba una relación directa con el sistema de fracturas y diaclasas. En otros casos el relieve interno de los tanques es mucho más suave y redondeado, lo que sugiere una relación más directa con procesos de corrosión química por debajo del frente de alteración en el contacto suelo-roca. Los tanques naturales pueden ser integrados al modelo polifásico propuesto por VIDAL ROMANÍ (2008), que propone un origen subsuperficial relacionado tentativamente con procesos subedáficos o, más verosímilmente, generados por la migración y concentración de cargas durante la intrusión del granito en la litosfera (VIDAL ROMANÍ, 2008). Posteriormente, estas depresiones iniciadas en profundidad, en condiciones confinantes, quedarán expuestas a los procesos exógenos aunque ya en condiciones subaéreas (Figura 3).

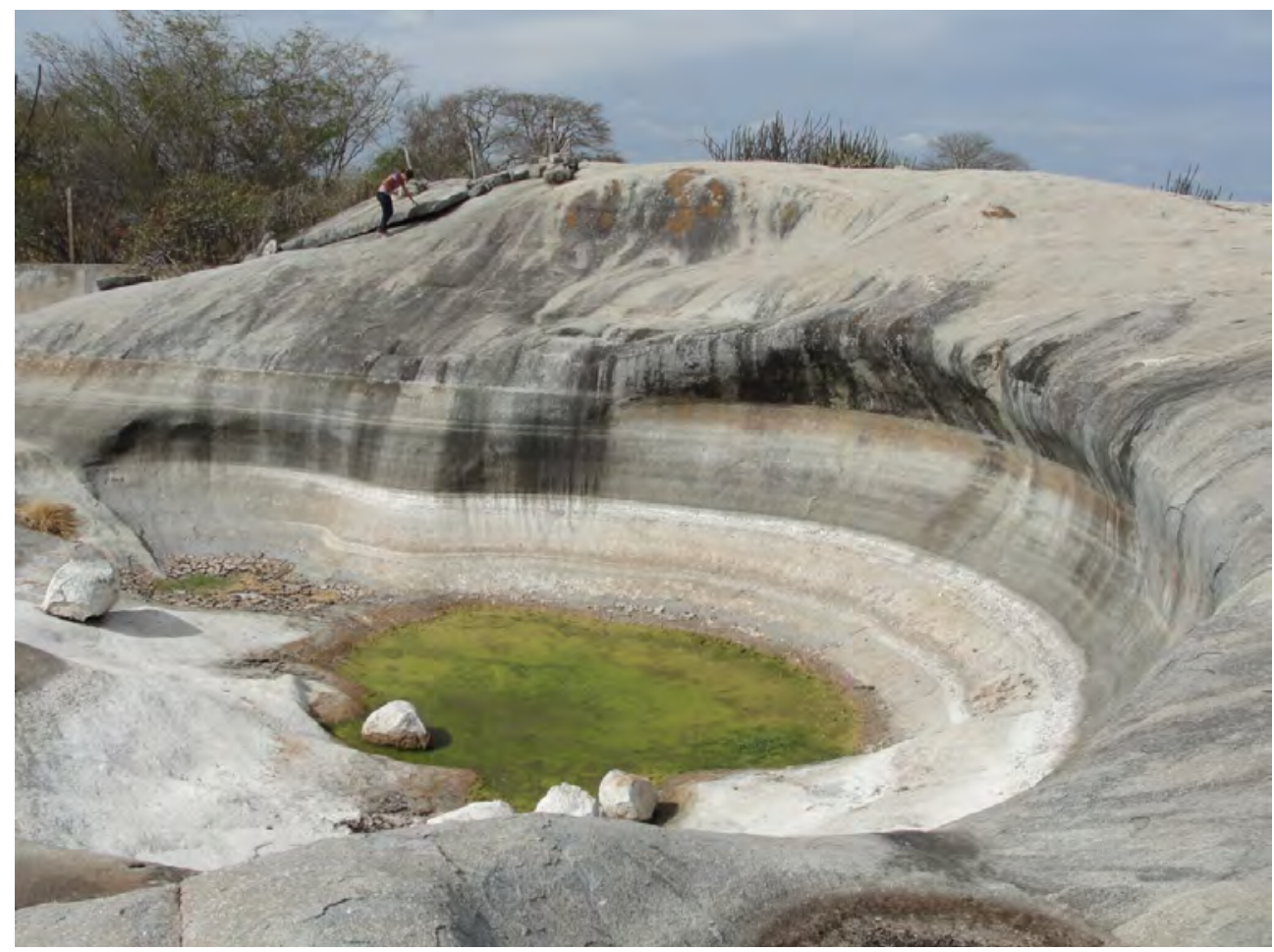

Fig. 3. Tanque natural con paredes escarpadas y con el desarrollo de un exutório a la izquierda de la fotografía. Esta forma se ha desarrollado en el borde de un domo granítico en la localidad de Curimatãs, municipio de Pocinhos, Estado de Paraíba; se aprecia su formación por la coalescencia de cavidades que le dan un aspecto lobulado al tanque (Foto: Hermínio de Araújo-Júnior). 
Los tanques naturales pueden variar de forma y tamaño en el relieve granítico en el noreste brasileño. En algunos casos los tanques naturales son el resultado de coalescencia de dos o más cavidades, creando formas lobuladas en el terreno graníticognéisico. Según VIDAL ROMANÍ \& TWIDALE (1998) las formas análogas a los tanques llegan a orden de 1 metro y con profundidad media de 0,5 metro. Sin embargo una gran parte de los tanques naturales estudiados en Brasil poseen mayores dimensiones. En XIMENES (2009) se han analizado y registrado cavidades con dimensiones que varían entre 10 a 20 metros de longitud, 5 a 8 metros de anchura y con profundidades alcanzando los 10 metros (Figuras 4, 5 y 6). 


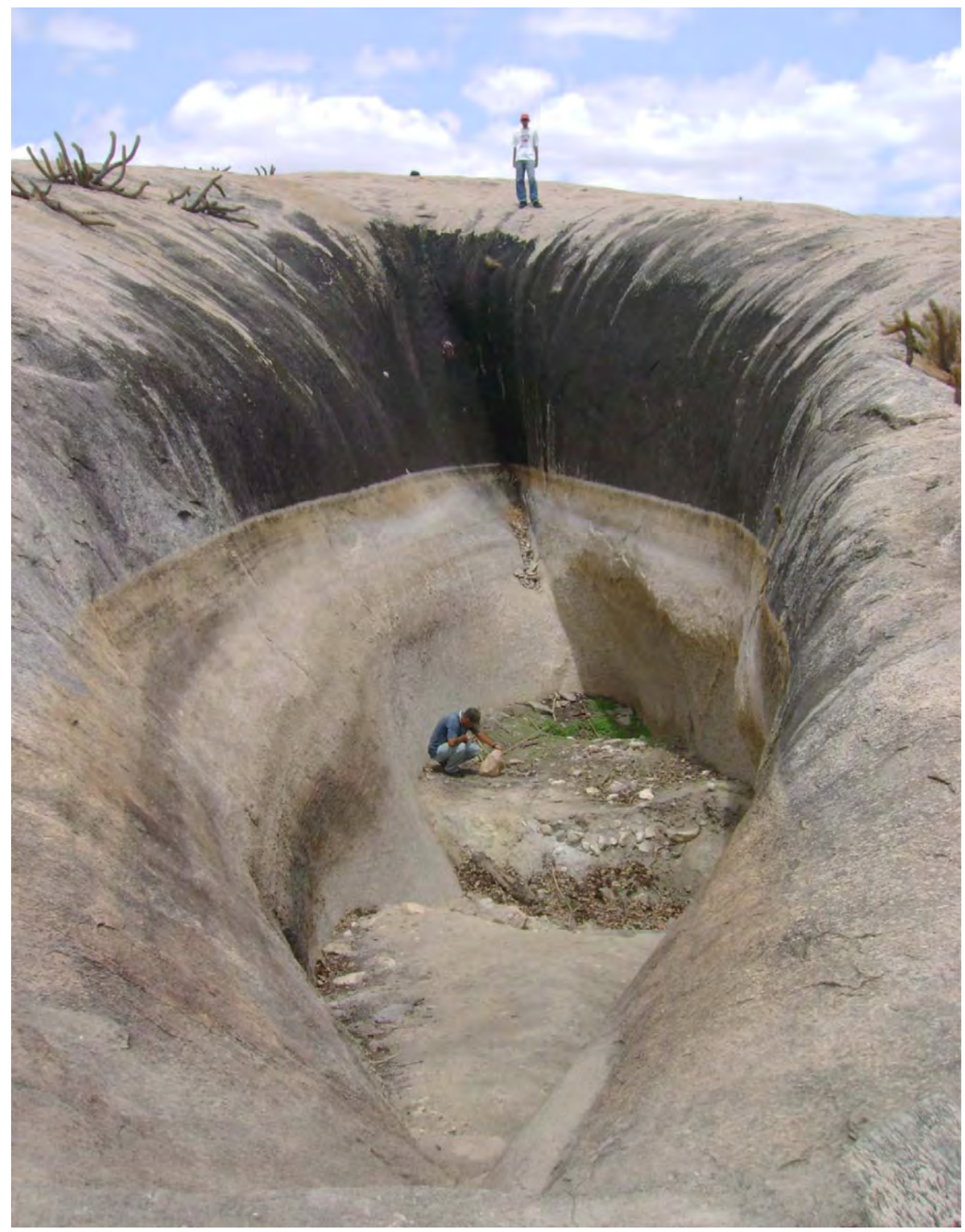

Fig. 4. Tanque natural escarpado de gran profundidad ubicado en el Sítio Paleontológico Lajinhas, municipio de Itapipoca, Estado de Ceará. La fotografía ha sido tomada desde la zona de desagüe de la cavidad (exutorio) lo que da al tanque un aspecto de sillón (Foto: Celso Lira Ximenes). 


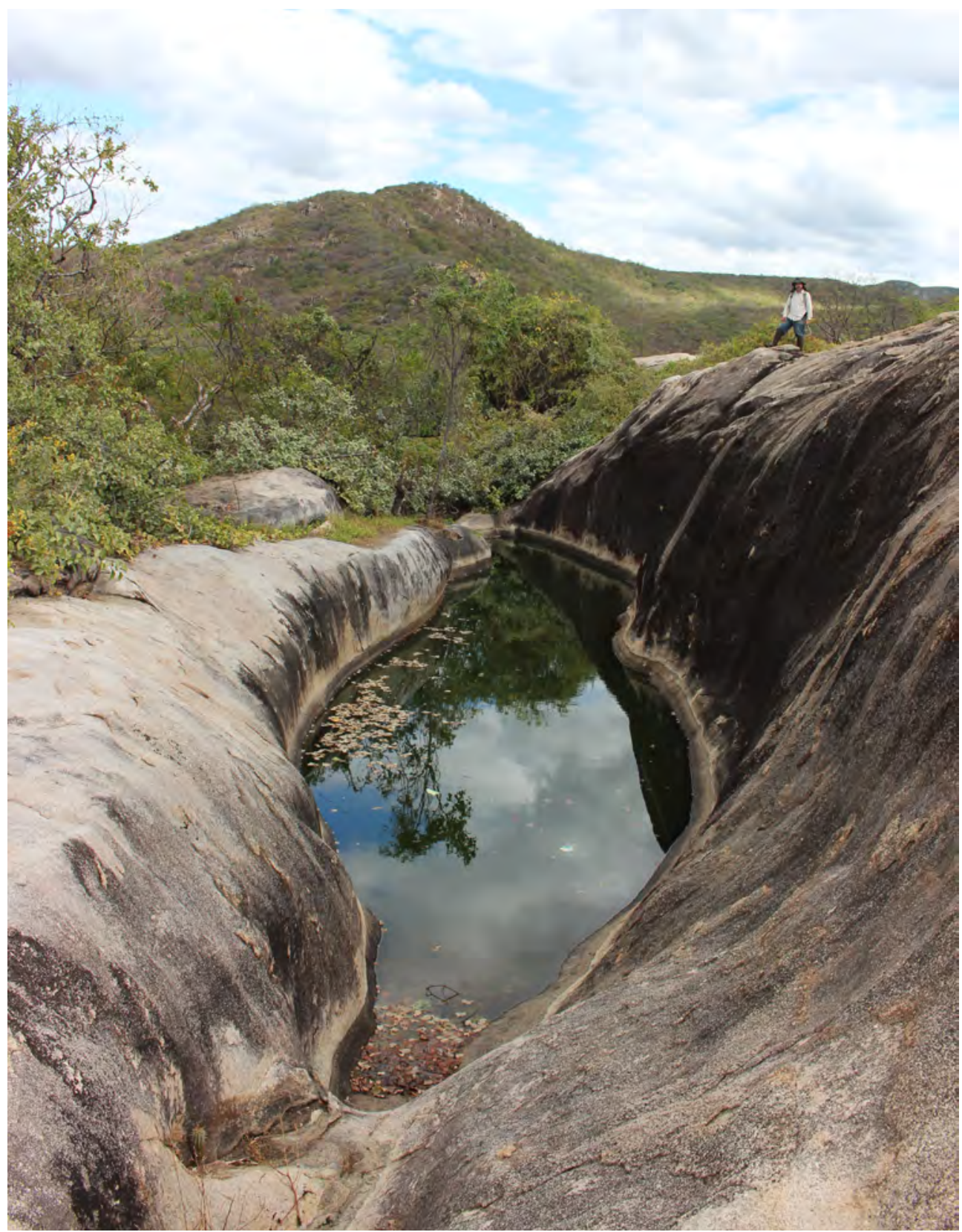

Fig. 5. Tanque natural escarpado de gran profundidad en el Sítio Paleontológico João Cativo, municipio de Itapipoca, Estado de Ceará. Los tanques naturales han sido utilizados históricamente como reservatorios de agua en épocas de sequía en Noreste de Brasil (Foto: Felipe Rodrigues Waldherr). 


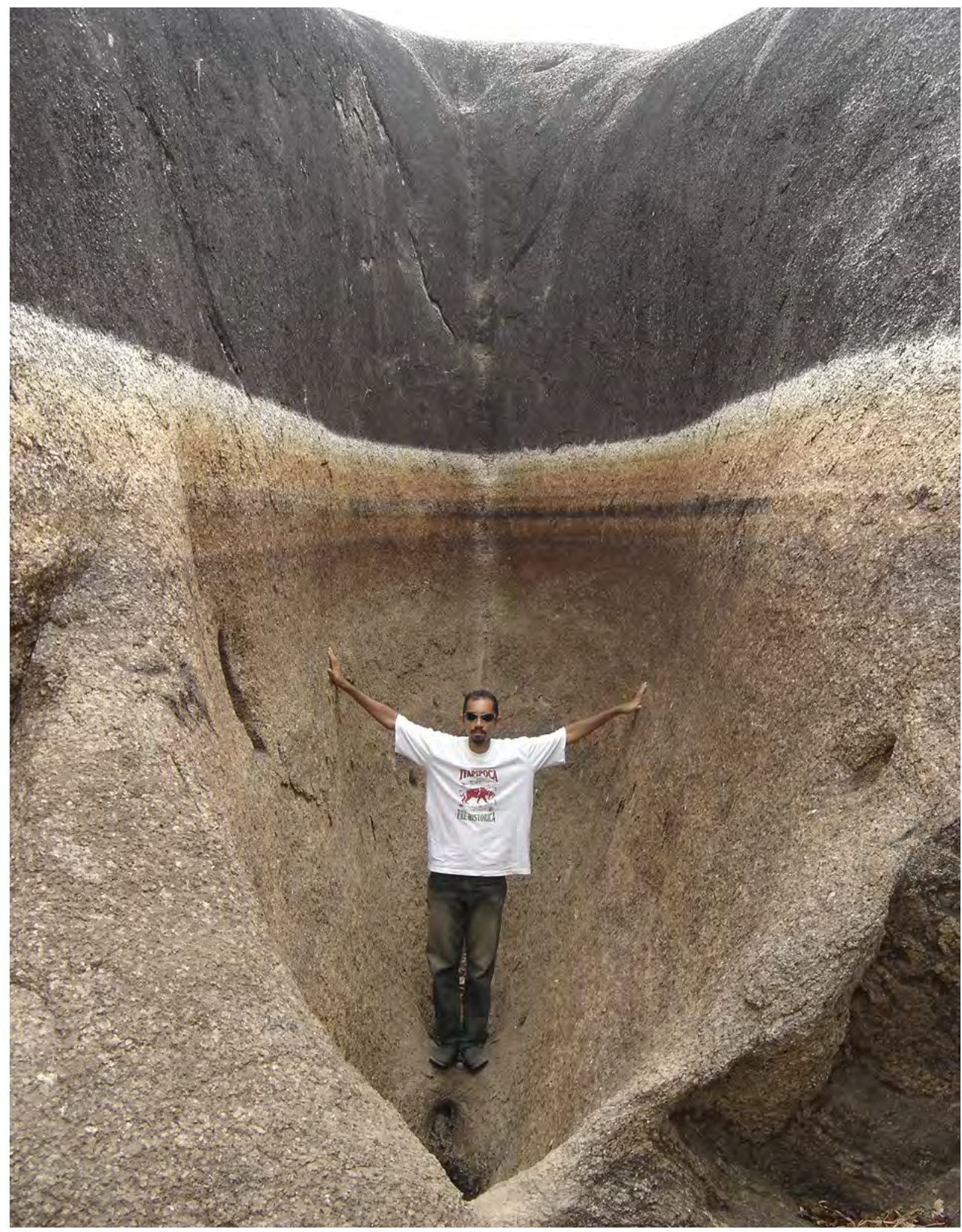

Fig. 6. La parte interna de um tanque natural escarpado de gran profundidad en el Sítio Paleontológico Jirau, municipio de Itapipoca, Estado de Ceará. Es posible notar el control estructural por la fractura-diaclasa y la morfología de fondo cóncavo (Foto: Celso Lira Ximenes). 
Los tanques naturales y sus depósitos fosilíferos constituyen importantes yacimientos paleontológicos y, eventualmente, arqueológicos en el Noreste de Brasil (SANTOS JÚNIOR, 2005; SANTOS JÚNIOR et al., 2008; 2015). Por ejemplo en el municipio de Itapipoca, parte norte del Estado de Ceará, los tanques naturales son formas frecuentes en torno del macizo residual de Uruburetama, conformando estrechas depresiones colmatadas por depósitos sedimentarios donde, ocasionalmente, aparecen o se conservan restos de la megafauna del Cuaternario (Figuras 7, 8 y 9). Según los estudios de XIMENES (2003, 2006b, 2009, 2011) las características geológicas y geomorfológicas locales han favorecido la formación de una de las más grandes concentraciones de este tipo de cavi- dades asociadas a depósitos paleontológicos de todo Brasil, distribuidas en un área superior a los $800 \mathrm{~km}^{2}$ sobre el basamento cristalino. Según este autor las condiciones paleoclimáticas fueron favorables para el desarrollo de una fauna diversificada de vertebrados y (ver XIMENES 2009) en Itapipoca se han encontrado más de 30 taxons ya identificados de mamíferos, reptiles, anfibios y aves. En virtud de la concentración de depósitos fosilíferos en los tanques naturales, junto con el abundante material paleontológico recogido y expresiva representatividad de diferentes especies paleomamíferas, el área ubicada entre las drenajes de los ríos Cruxati y Mundaú, en municipio de Itapipoca, se ha llamado también como el "Valle de la Megafauna" (XIMENES, 2003, 2006b, 2009).

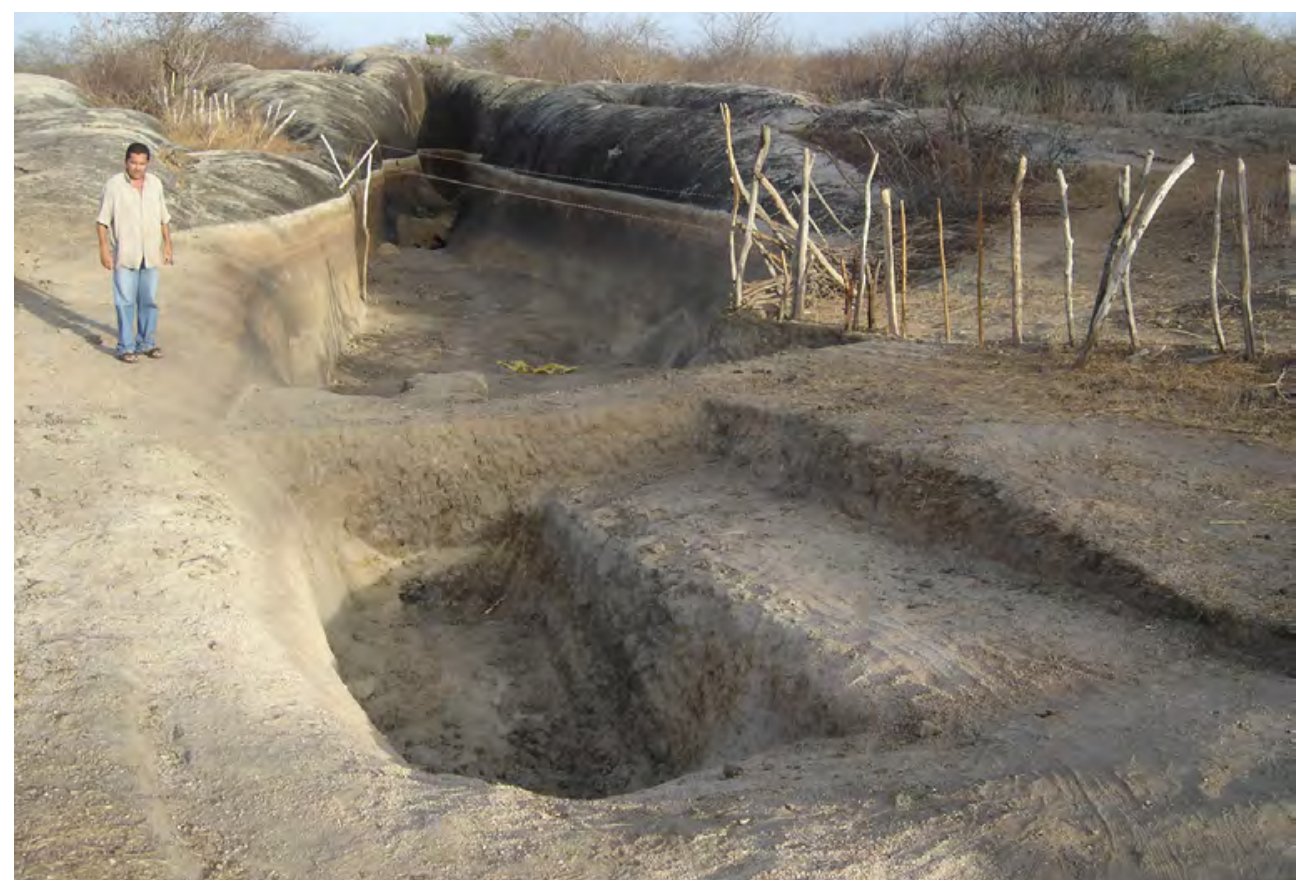

Fig. 7. Proceso de apertura de una cacimba sobre el depósito sedimentario de un tanque natural en el Sítio Paleontológico Jirau, municipio de Itapipoca, Estado de Ceará (Foto: Celso Lira Ximenes). 


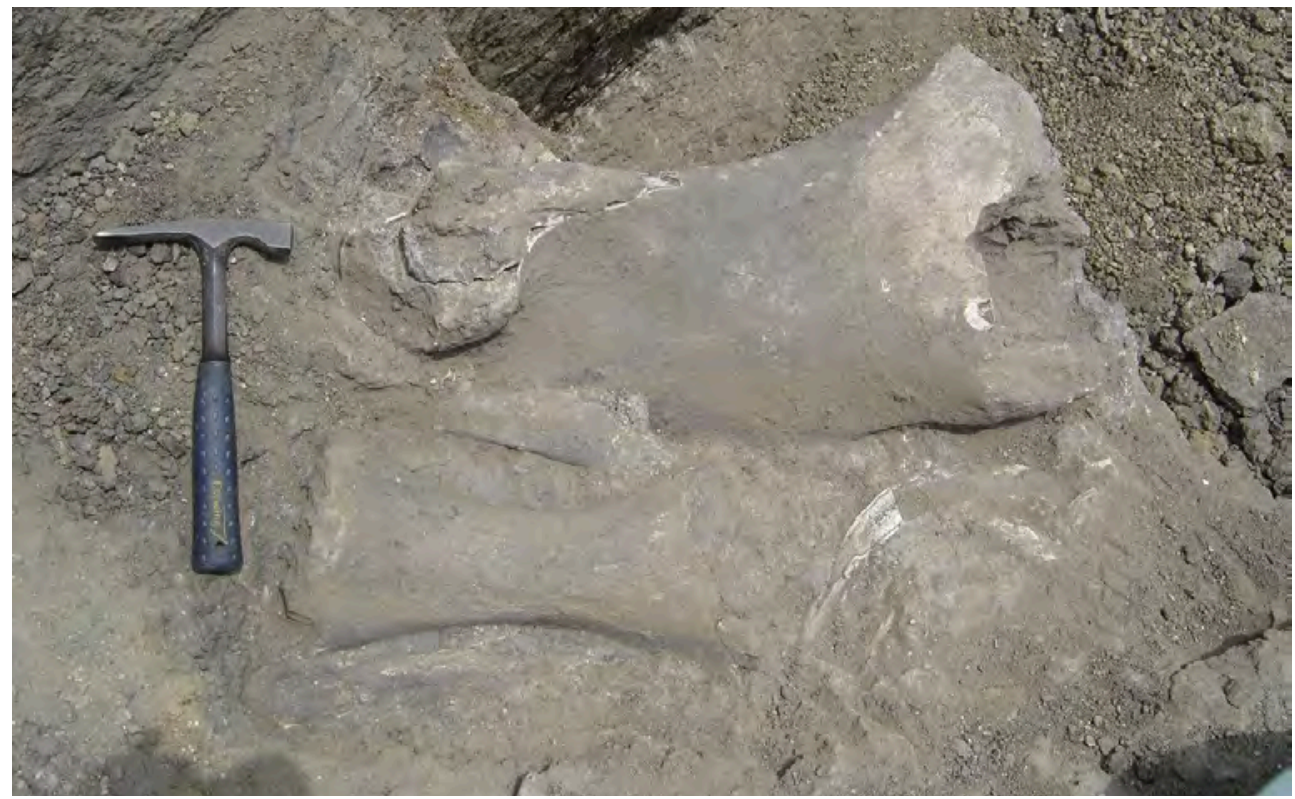

Fig. 8. Restos fósiles (fémur y tibia) de un perezoso-gigante (Eremotherium laurillardi) dentro del depósito de un tanque natural. Este tanque es conocido como Jirau 1, y está ubicado en el yacimiento paleontológico Jirau, municipio de Itapipoca, Estado de Ceará. El contenido fosilífero fue recogido en el año 2006 por el Profesor Celso Lira Ximenes (Foto: Celso Lira Ximenes).

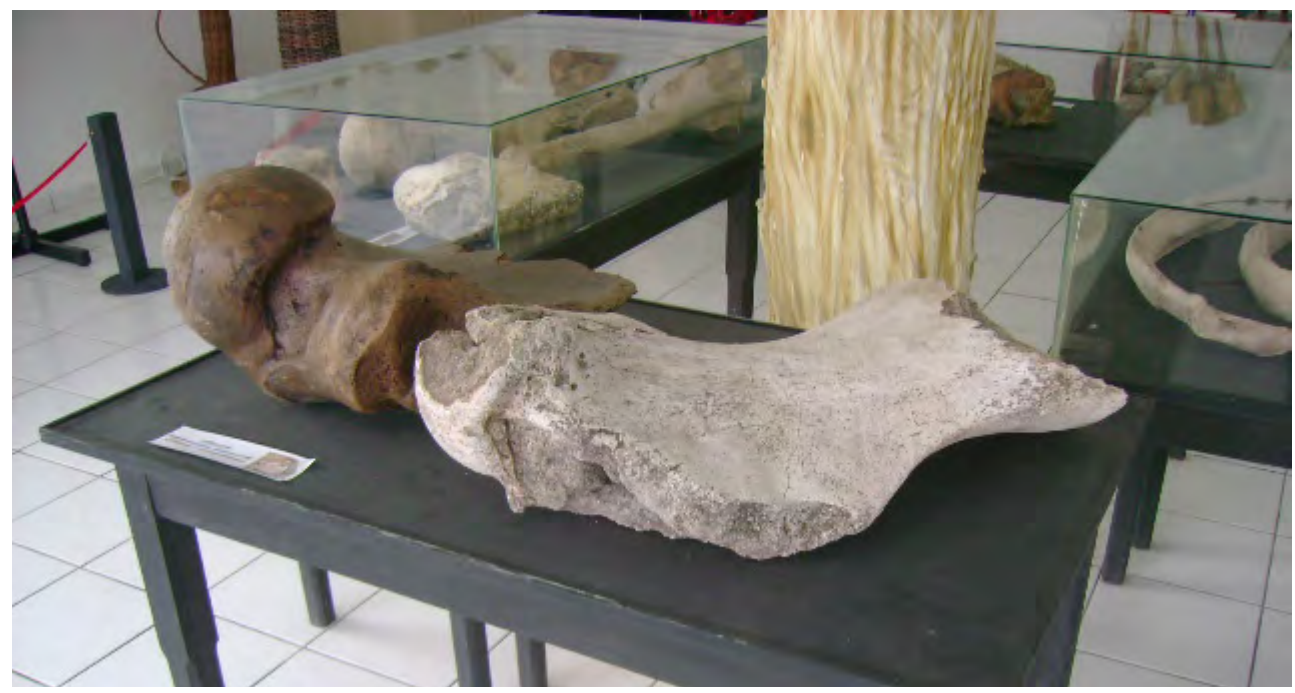

Fig. 9. Restos fósiles (dos ejemplares de fémur) del perezoso-gigante (Eremotherium laurillardi) expuestos en el Museu de Pré-História de Itapipoca (MUPHI), município de Itapipoca, Estado de Ceará (Foto: Celso Lira Ximenes). 


\section{Terminologías}

Las primeras referencias sobre los tanques (lato sensu) en la literatura brasileña datan de finales del siglo XVIII y principios del siglo XIX, y se refieren a la apertura de las depresiones por parte de los habitantes locales con la finalidad de construir depósitos de agua en épocas de sequía, que resultaban en hallazgos inesperados de contenido fósil de mamíferos cuaternarios (CASAL, 1817 a y b; HENDERSON, 1821; SPIX \& MARTIUS, 1824, 1928, GRAHAM, 1824; BURLAMAQUE, 1855, 1856; KRATIF, 1858; CAPANEMA, 1866; HARTT, 1870; BRANNER, 1902, 1915; ver también XIMENES, 2006a, FERNANDES et al., 2012, 2013a, 2013b y referencias incluidas). A lo largo de los siglos, en Brasil, los tanques ya fueron denominados de diversas maneras: cacimbas, caldeirões, oriçangas, panelas, potes, buracos, bacias de dissolução o depressões de intemperismo.

Entre los años 1848 y 1862, el Museo Nacional emprendió varias expediciones científicas hacia el Noreste del país (FERNANDES et al. 2010). El resultado de esta iniciativa fue el rescate de una cantidad considerable y variada de fósiles de la megafauna brasileña. En 1855, el coordinador del Museo Nacional, Frederico Burlamaque, recibió un total de 85 ataúdes que contenían huesos fósiles, y una de las remesas más voluminosas había sido recuperada de un poblado llamado Tanque de Aldeia y de regiones circundantes a Alagoas (FERNANDES et al. 2010, 2012). En 1853, otra remesa fue enviada desde la localidad llamada Caldeirão, municipio de Santa Brígida, Bahía. Sin embargo, el abundante material asociado al contenido fosilífero nunca se registró en la recepción oficial del Museo Nacional (FERNANDES et al. 2010, 2012). Otras lo- calidades de las que proceden materiales fosilíferos, rescatados de tanques naturales durante el mismo período de tiempo, fueron: Tanque Velho y Tanque dos Elefantes, municipio de Pão de Açúcar, en Alagoas, y el poblado de Tanque Velho, en Sitios Nuevos, de Canhoba, en Sergipe (FERNANDES et al. 2012). Se puede plantear la hipótesis de que la generalización del término tanque (y calderão) está también asociada a los nombres de las localidades, donde los primeros fósiles fueron recuperados de manera sistemática en Brasil.

De acuerdo con OLIVEIRA (1989) el término tanque fue empleado por primera vez por Luciano Jacques de Moraes en 1924, en el trabajo titulado Serras e Montanhas do Nordeste. Sin embargo, trabajos más antiguos, como del Cura Manuel Aires de Casal, en 1817, ya utilizaban el término tanque asociado a las pequeñas depresiones (CASAL, 1817 a y b, FERNANDES et al., 2013b). Los naturalistas Spix y Martius, en sus escritos originales en lengua germana mantuvieron los términos tanques y caldeirões (SPIX \& MARTIUS, 1828, 1968), mientras que en los trabajos elaborados en lengua inglesa (HARTT, 1870, BRANNER, 1902) se utilizaron los términos tanks, cauldrones, pot-holes y rock basins. Posteriormente, los trabajos en lengua inglesa fueron traducidos, y mantuvieron los términos tanques y caldeirões, siendo publicados, respectivamente, en 1941 por la Editora Nacional y en 1948 en el periódico Boletim Geográfico (HARTT, 1941, BRANNER, 1948).

A pesar de la clasificación morfológica, varios términos han sido verificados en la literatura en lengua inglesa, a ejemplo de Rock Basins, Rock Holes, Weather Pits, Water Eyes, Pot Holes, Cauldrones o Granite Pits. El término gnamma de origen abo- 
rigen en Australia, traducido al portugués como "pozo de agua", ha sido aceptado y utilizado a nivel internacional (BIGARELLA, 1994; TWIDALE Y CAMPBELL, 2005). En España se llaman Pílas, Hoyos, Cazuelas y Pilancones, en Galicia (España) y en Portugal se denominan Pías, y en Cataluña (España) Cadolles o Cassoletes. En estudios realizados en Angola por el geógrafo portugués, Profesor Ilídio de Amaral, las cavidades fueron llamadas como Oriçangas (AMARAL, 1973, 1974). Según VIDAL ROMANÍ \& TWIDALE (1998) en francés se llaman Tanques y Vasques Rocheuses; en alemán se denominan Verwitterrungsnäpfe, Opferkessel, Baumverfallspingen, Felsschüssel y Dellen; y en polaco, de Kociolli.

Importancia de los tanques naturales en la paleontología

El descubrimiento de restos fósiles preservados en los tanques naturales del Noreste de Brasil marcó un hito en la historia del desarrollo de la Paleontología en América del Sur. En el año 1784, el entonces gobernador de la capitanía de Ceará, João Batista de Azevedo Coutinho de Montaury, fue el responsable de enviar los fósiles recogidos de los tanques naturales del valle del Río Acaraú, municipio de Sobral, actual Estado de Ceará, para el Reino de Portugal, específicamente para el Museu Real da Ajuda, en Lisboa. Los fósiles en cuestión corresponden al primer descubrimiento documentado, a nivel epistolar, de la megafauna pleistocénica de Brasil (FERNANDES et al. 2013a). A principios del siglo XIX, el cura portugués Manuel Aires de Casal realizó uno de los primeros registros sobre la aparición de fósiles de animales "de la antigüedad" que se encontraron en los tanques del Noreste de Brasil (CASAL, 1817 a y b; FERNANDES et al., 2013b). En la clásica obra titulada Reise in Brasilien (Viagem pelo Brasil, 1817-1820), escrita por los naturalistas alemanes Spix y Martius, se realizó una de los primeros registros de fósiles recogidos de la megafauna del Cuaternario. Los restos fósiles, que fueron encontrados y retirados de tanques cercanos a la Serra de Itauba y en la localidad de Monte Santo, en el interior del Estado de Bahía, correspondían a la "parte craneal" y al "fémur de un mastodonte" (SPIX \& MARTIUS, 1824, 1828). Durante los siglos XIX y XX, innumerables expediciones organizadas por el Museo Nacional partieron de Río de Janeiro hacia el Noreste del país con la finalidad de recolectar y transportar los fósiles a la antigua capital del Imperio de Brasil. De los investigadores extranjeros que llegaron a principios del siglo pasado a observar la singularidad de los tanques, se destaca el estadounidense John Casper Branner. Este geólogo también llegó a describir los fósiles de mamíferos hallados en el interior de Pernambuco y de Alagoas (BRANNER, 1902).

Recientemente, ARAÚJO-JÚNIOR et al. (2013a) distinguieron los tanques naturales de los depósitos de tanque. Para estos autores, los tanques naturales consisten en las depresiones producidas por el proceso de meteorización físico-química de las rocas del basamento, mientras que los depósitos de tanque comprenden el contenido sedimentario que rellenó esas depresiones durante el Pleistoceno Final - Holoceno inicial. El estudio de las acumulaciones fosilíferas de esos depósitos configura una de las principales herramientas para el entendimiento de las condiciones paleoambientales y los aspectos paleoecológicos de la Región Intertropical Brasileña (RIB; sensu CARTELLE, 1999) durante el Cuaternario. 
Estos depósitos están generalmente estratificados y son fosilíferos preservándose en ellos restos de una diversificada fauna que incluye principalmente la megafauna desde el Pleistoceno Final al Holoceno inicial, por ejemplo: megateriítidos, gliptodósidos, gonfoteriídeos, toxodósidos, macrauqueniídeos y felídeos. En algunos casos, los fósiles de la megafauna están asociados a restos de pequeños mamíferos, anfibios, cocodrilos, quelonios, lagartos y aves. En la Tabla 1 se presenta una lista de todos los grupos de vertebrados que fueron identificados hasta el momento en los depósitos hallados en tanques del Noroeste de Brasil.

Los depósitos de tanque son el tipo más singular de depósito fosilífero hallado hasta el momento en América del Sur. Eventualmente los tanques naturales desarrollados en rocas de basamento del Noreste de Brasil conservan en su interior pequeños cuerpos sedimentarios fosilíferos de edad cuaternaria. La mayor parte de los fósiles de la megafauna pleistocena conocida en el Noroeste de Brasil ha sido encontrada en depósitos de tanque (ARAÚJO-JÚNIOR \& PORPINO, 2011; ARAÚJO-JÚNIOR et al., 2013a), aunque otros, proceden de una amplia variedad de tipos de depósitos comunes en la región, por ejemplo, cuevas, lagunas, ojos de agua y diques (BERGQVIST et al., 1997; OLIVEIRA et al., 2014).

La secuencia de formación de este tipo de depósitos fosilíferos es indudablemente compleja puesto que la sedimentación se producirá solo una vez que se haya desarrollado la concavidad. Ello hace suponer que ya en el Pleistoceno estaban formados los tanques y además libres de sedimentos y por tanto de restos fósiles. La estratificación observada en los depósitos indica que el proceso sedimentario se realizó en el seno del agua por lo que eventualmente los tanques actuaron como zonas de acumulación de agua adonde concurrían los distintos organismos que terminaron muriendo alli, acumulándose sus restos en el tanque que serían recubiertos posteriormente por sedimentos. 


\begin{tabular}{|l|l|l|}
\hline Mamíferos & Proboscidea & Reptiles \\
\hline Xenarthra - Pilosa & Notiomastodon* & Testudines \\
\hline Eremotherium* & Notoungulata & Geochelone*** \\
\hline Glossotherium** & Toxodon* & Crocodylia \\
\hline Catonyx* & Perissodactyla & Caimaninae indet.** \\
\hline Ocnotherium* & Equus* & Ophidia \\
\hline Nothrotherium** & Hippidion* & Ophidia indet.*** \\
\hline Xenarthra -Cingulata & Tayassu** & Lacertilia \\
\hline Glyptotherium* & Artiodactyla & Lacertilia indet.*** \\
\hline Panochthus* & Palaeolama* & Aves \\
\hline Glyptodon* & Mazama** & Rheiformes \\
\hline Hoplophorus* & Ozotocerus** & Rhea?** \\
\hline Neuryurus* & Blastocerus** & Acciptriformes \\
\hline Pampatherium* & Carnivora & $\begin{array}{l}\text { Acciptriformes } \\
\text { indet.*** }\end{array}$ \\
\hline Holmesina* & Smilodon* & Anfibios \\
\hline Dasypus*** & Panthera** & Anura \\
\hline Euphractus*** & Leopardus*** & Rhinella*** \\
\hline Tolypeutes*** & Protocyon** & \\
\hline Pachyarmatherium** & Cerdocyon*** & \\
\hline Litopterna & & \\
\hline Xenorhinotherium* & & \\
\hline
\end{tabular}

Tabla 1. Diversidad de los vertebrados identificados en los depósitos de tanque del Noreste de Brasil. * vertebrados con un tamaño superior a $100 \mathrm{~kg}$; ** vertebrados con un peso entre $10 \mathrm{~kg}$ y $100 \mathrm{~kg} ; * * *$ vertebrados con un peso menor que $10 \mathrm{~kg}$ (fuente: PAULA-COUTO, 1980; BERGQVIST et al. 1997; DANTAS et al. 2005; SILVA, 2008; OLIVEIRA et al. 2009; ARAÚJO-JÚNIOR \& PORPINO, 2011, ARAÚJO-JÚNIOR et al. 2013a, 2013b, 2015; RIBEIRO, 2014; SILVA, 2014).

\section{CONCLUSIÓN}

Los tanques naturales (stricto sensu) constituyen importantes formas menores -medias en el relieve granítico del noreste brasileño. El descubrimiento de un importante registro fósil en depósitos sedimentarios dentro de estos tanques naturales, y que ha sido recogido en documentación epistolar que data del siglo XVIII, configura un marco relevante para el desarrollo de la Paleontología en Brasil. En general, los tanques naturales tienden a preservar el contenido fósil debido a su profundidad, capacidad de retención de material sedimentado transportado y forma similar a un refugio, resguardando los fósiles de la meteorización. El levantamiento sistemático de datos realizado en la década de 1850 por el Museo Nacional, junto con los estudios académicos posteriores sobre tanques naturales y depósitos contenidos en 
esos tanques suministran una información muy valiosa, de carácter estratigráfico, sedimentológico y paleontológico, ayudando a la interpretación parcial de las condiciones paleoambientales y de paleofauna que predominaron durante el Pleistoceno Final en el Noreste del Brasil.

Agradecimientos: Al equipo de la Biblioteca do Centro de Tecnologia e Ciência (CTC / C) y al Núcleo de Memória, Informação e Documentação (MID) de la Universidade do Estado do Rio de Janeiro (UERJ) por auxiliar la investigación documental y poner a disposición las obras utilizadas; al equipo de la Biblioteca Professor Maurício de Almeida Abreu del Programa de Pós-graduação em Geografia de la Universidade Federal do Rio de Janeiro (PPGG-UFRJ) por poner a disposición y auxiliar con las obras necesarias para la elaboración del presente trabajo académico; al Profesor Dr. Juan Ramón Vidal Romaní, del Instituto Universitario de Geología Isídro Parga Pondal, de la Universidad de La Coruña - España, por haber colaborado con la revisión y un análisis crítico de este artículo.

\section{BIBLIOGRAFÍA}

ALKMIM, F.F. 2004. O que faz de um cratón um cratón? O Cratón do São Francisco e as revelações almedianas ao delimitá-lo. In: Mantesso-Neto, V, Bartorelli, A., Carneiro, C.D.R. \& Brito Neves, B.B. (Ed.). Geologia do Continente Sul-Americano: Evolução da Obra de Fernando Flávio Marques de Almeida. São Paulo, Editora Beca, p. 17-36.

ALMEIDA, F.F.M., HASUY, Y., BRITO NEVES, B.B., FUCK, R.A. 1981. Brazilian structural provinces: An introduction. Earth-Science Reviews, 17: 1-21.
AMARAL, I. 1973. Formas de «Inselberge» (ou montes-ilhas) e de meteorização superficial e profunda em rochas graníticas do Deserto de Moçâmedes (Angola), na margem direita do Rio Curoca. Garcia de Orta - Série de Geografia, 1(1): 1-34.

AMARAL, I. 1974. A propósito de formas escavadas em leitos fluviais e em vertentes de rochas graníticas do Deserto de Moçâmedes (Angola), na margem direita do Rio Curoca. Garcia de Orta - Série de Geografia, 2(1): 1-18.

ARAÚJO-JÚNIOR, H.I., PORPINO, K.O. 2011. Assembléias fossilíferas de mamíferos do Quaternário do Estado do Rio Grande do Norte, Nordeste do Brasil: Diversidade e aspectos tafonômicos e paleoecológicos. Pesquisas em Geociências, 38: 67-83.

ARAÚJO-JÚNIOR, H.I. 2016. Classifying vertebrate assemblages preserved in Quaternary tank deposits: Implications for vertebrate taphonomy and paleoecology. Palaeogeography, Palaeoclimatology, Palaeoecology, 445: 147-152.

ARAÚJO-JÚNIOR, H.I., PORPINO K.O., BERGQVIST, L.P. 2013b. Taphonomic analysis of a late Pleistocene vertebrate accumulation from Lage Grande Paleontological Site, Pernambuco State, northeastern Brazil: New remarks on preservational aspects of tank deposits. Quaternary International, 317: 88-101.

ARAÚJO-JÚNIOR, H.I., PORPINO, K.O., BERGQVIST, L.P. 2015. Vertebrate taphonomy and paleoecology in an Upper Pleistocene tank deposit of Paraíba, Brazil: Taphonomic modes, evidence of temporal and spatial resolutions and paleoecological patterns of the Brazilian Intertropical Region. Palaeogeography, 
Palaeoclimatology, Palaeoecology, 437: 1-17.

ARAÚJO-JÚNIOR, H.I., PORPINO, K.O., XIMENES, C.L., BERGQVIST, L.P. 2013a. Unveiling the taphonomy of natural tank deposits: a case study in the Pleistocene of northeastern Brazil. Palaeogeography, Palaeoclimatology, Palaeoecology, 378: 52-74.

ARAÚJO-JÚNIOR, H.I., PORPINO, K.O., XIMENES, C.L., BERGQVIST, L.P. 2013a. Unveiling the taphonomy of natural tank deposits: a case study in the Pleistocene of northeastern Brazil. Palaeogeography, Palaeoclimatology, Palaeoecology, 378: 52-74.

ARCHANJO, C.J., HOLLANDA, M.H.B.M., RODRIGUES S.W.O., BRITO NEVES, B.B., ARMSTRONG, R. 2008. Fabrics of pre and syntectonic granite plutons and chronology of shear zones in the Eastern Borborema Province, NE Brazil. Journal of Structural Geology, 30: 310-336.

BARRETO, A. M. F., SILVA, F.M., ALMEIDA, J.A.C., SILVA, A.C.B.L. 2004. Os depósitos de cacimbas de Pernambuco: Aspectos geomorfológicos, geológicos, paleontológicos e paleoambientais. In: XLII Congresso Brasileiro De Geologia. 42., Minas Gerais, Anais, 1-2, 2004.

BERGQVIST, L.P., GOMIDE, M., CARTELlE, C., CAPILlA, R. 1997. Faunas-locais de mamíferos pleistocênicos de Itapipoca/Ceará, Taperoá/Paraíba e Campina Grande/Paraíba. Estudo comparativo, bioestratinômico e paleoambiental. Geociências, 2(6): 23-32.

BIGARELLA, J.J. 1994. Estrutura e origem das paisagens tropicais e subtropicais volume 1. Florianópolis, Editora da UFSC, $425 \mathrm{p}$
BRANNER, J.C. 1902. On the occurrence of fossil remains of mammals in the interior of the States of Pernambuco and Alagoas, Brazil. American Journal of Science, 13: 133-137.

BRANNER, J.C. 1915. Geologia elementar. Rio de Janeiro, Livraria Francisco Alves, 404p.

BRANNER, J.C. 1948. Da ocorrência de restos de mamíferos fósseis no interior dos Estados de Pernambuco e Alagoas. Boletim Geográfico, 68: 941-943.

BRITO NEVES, B.B., SANTOS, E.J., VAN SCHMUS, W.R. 2000. Tectonic history of the Borborema Province. In: Cordani, U.G., Milani, E.J., Thomaz Filho, A. \& Campo, D.A. (Ed.). Tectonic evolution of the South America. Rio de Janeiro, Sociedade Brasileira de Geologia, p. 151182.

BURLAMAQUE, F.L.C. 1855. Notícia acerca dos animaes de raças extinctas descobertos em vários pontos do Brasil. Trabalhos da Sociedade Vellosiana, 20: 1-16.

BURLAMAQUE, F.L.C. 1856. Notícia acerca dos animaes de raças extinctas descobertos em vários pontos do Brasil. Trabalhos da Sociedade Vellosiana, 20: 17-21.

CAMPBELL, E.M., TWIDALE, C.R. 1995. The various origins of minor granite landforms. Cadernos do Laboratorio Xeolóxico de Laxe, 20: 281-306.

CAPANEMA, G.S. 1866. Decomposição de penedos no Brasil. Lição popular proferida em 25 de junho, Rio de Janeiro, $32 \mathrm{p}$.

CARTELLE, C. 1999. Pleistocene mammals of the Cerrado and Caatinga of Brazil. In: Eisenberg, J.F. \& Redford, K.H. (Ed.). Mammals of the Neotropics: 
The Central Neotropics. Chicago, The University of Chicago Press, p. 27-46.

CASAL, M.A. 1817a. Corografia brazilica, ou Relação historico-geografica do Reino do Brazil. Rio de Janeiro, Impressão Régia, 182p.

CASAL, M.A. 1817b. Corografia brazilica, ou Relação historico-geografica do Reino do Brazil. Rio de Janeiro, Impressão Régia, 158p.

CORREAA, A. C.B., TAVARES, B.A.C., MONTEIRO, K.A., CAVALCANTI, L.C.S., LIRA, D.R. 2010. Megageomorfologia e morfoestrutura do Planalto da Borborema. Revista do Instituto Geológico - São Paulo. 31(1/2): 35-52.

DANTAS, M.A.T., ZUCON, M.H. \& RIBEIRO, A.M. 2005. Megafauna pleistocênica da Fazenda Elefante, Gararu, Sergipe, Brasil. Geociências, 24: 277-287.

FERNANDES, A.C.S., EWBANK, C.O., SILVA, M.J., HENRIQUES, D.D.R. 2010. Uma lembrança de infância: os "fósseis colossais" e o papel de Frederico Leopoldo César Burlamaque como paleontólogo brasileiro. Filosofia e História da Biologia, 5(2): 239-259.

FERNANDES, A.C.S., RAMOS, R.R.C., SILVA, J.L.L., SILVA A.P.L. 2012. Do Nordeste para o Rio de Janeiro: Os tanques das primeiras remessas de fósseis de megafauna enviadas ao Museu Nacional. In: SIMPÓSIO BRASILEIRO DE PALEONTOLOGIA DE VERTEBRADOS, 7, 2012, Recife. Boletim de Resumos. Recife, SBPV, Edição Especial, p. 63-63.

FERNANDES, A.C.S., XIMENES, L.C., ANTUNES, M.T. 2013a. Na Ribeira do Acaraú: João Batista de Azevedo Coutinho de Montaury e a descoberta documentada de megafauna no Ceará em 1784. Filosofia e História da Biologia, 8(1): 21-37.

FERNANDES, A.C.S., FARIA, F., ANTUNES, M.T. 2013b. Manuel Aires de Casal, o beemote de Jó e o registro das ocorrências fossilíferas brasileiras no início do século XIX. Filosofia e História da Biologia, 8(2): 133-150.

GRAHAM, M. 1824. Journal of a voyage to Brazil and residence there, during parto $f$ the years 1821, 1822, 1823. London, Printed for Longman, Rees, Orme, Brown, and Green, 335p.

HENDERSON, J. 1821. A history of the Brazil comprising its geography, commerce, colonization, aboriginal inhabitants. London, Published by Longman, Hurst, Rees, Orme and Brown, 522p.

HARTT, C.F. 1870. Geology and physical geography of Brazil. Boston, Fields, Osgood \& CO, 620p.

HARTT, C.F. 1941. Geologia e geografia física do Brasil. São Paulo, Editora Nacional, 649p.

MABESOONE, J.M., OLIVEIRA, L.D.D., DAMASCENO, J.M. 1990. Desenvolvimento dos tanques fossilíferos no Semiárido Norteriograndense. In: Congresso Brasileiro De Geologia, 36, Natal. Anais, Natal, SBG, v. 2, p. 733-741.

MAIA, R.P., BEZERRA, F.H.R. 2014. Condicionamento estrutural do relevo no nordeste setentrional brasileiro. Mercator, 13(1): 127-141.

MAIA, R.P. \& NASCIMENTO, M.A.L. 2018. Relevos graníticos do Nordeste brasileiro. Revista Brasileira de Geomorfologia, 19(2): 373-389.

MAIA, R.P., BASTOS, F.H., NASCIMENTO, M.A.L., LIMA, D.L.S., CORDEI- 
RO, A.M.N. 2018. Paisagens graníticas do nordeste brasileiro. Fortaleza, Edições UFC, 104p.

MORAES, L.J. 1924. Serras e montanhas do Nordeste. Rio de Janeiro, Inspetoria Federal de Obras Contra as Secas, 120p.

MORAES, L.J. 1928. Estudos geológicos no Estado de Pernambuco. Boletim do Serviço Geológico e Mineralógico do Brasil, 32:1-98.

OLIVEIRA, E.V., BARRETO, A.M.F., ALVES, R.S. 2009. Aspectos sistemáticos, paleobiogeográficos e paleoclimáticos dos mamíferos quaternários de Fazenda Nova, PE, Nordeste do Brasil. Gaea - Journal of Geoscience, 5: 75-85.

OLIVEIRA, L.D.D., HACKSPACHER, P.C. 1989. Gênese e provável idade dos tanques fossilíferos de São Rafael-RN. In: Congresso Brasileiro De Paleontologia, 11., 1989, Curitiba. Anais. Curitiba, SBP, v. 1, p. 541-549.

OLIVEIRA, L.D.D. 1989. Considerações sobre o emprego da terminologia da "formação cacimbas" e caldeirões para os tanques fossilíferos do Nordeste do Brasil. In: Congresso Brasileiro De Paleontologia, 11., 1989, Curitiba. Anais... Curitiba, SBP, v.1, p. 535-539.

OLIVEIRA, P.E., PESSENDA, L.C.R., BARRETO, A.M.F., OLIVEIRA, E,V., SANTOS, J.C. 2014. Paleoclimas da Caatinga brasileira durante o Quaternário Tardio. In: CARVALHO, I. (Ed.). Paleontologia: Cenários de Vida - Paleoclimas. Interciência, Rio de Janeiro, volume 5, p. 501-516.

PAULA-COUTO, C. 1980. Fossil Pleistocene to sub-recent mammals from northeastern Brazil. I-Edentata Megalonychidae. Anais da Academia Brasileira de Ciências, 52(1): 144-151.
RIBEIRO, R.C. 2014. Assembléia fossilifera do Quaternário tardio de Lagoa do Rumo, Baixa Grande, Bahia: Tafonomia e Geocronologia. Rio de Janeiro, 150 p. Tese de Doutorado, Programa de Pósgraduação em Geologia, Instituto de Geociências, Universidade Federal do Rio de Janeiro.

RODRIGUES, S.W.O., ARCHANJO, C.J., GROHMANN, C.H. 2010. Quantificação da deformação finita nos metagranitoides Cariris Velhos na região de Alagoa Grande (PB). Geologia USP Série científica, 10(3): 57-78.

SANTOS JÚNIOR, V. 2005. Os Registros Rupestres da Área Arqueológica de Santana ( $R N)$. Dissertação de Mestrado. Universidade Federal de Pernambuco: Instituto de Ciências Humanas: Programa de Pós-Graduação em Arqueologia. 2005. 229p.

SANTOS JÚNIOR, V., PORPINO, K. O., ABRAAHÃO, S. 2008. A megafauna extinta e os artefatos culturais de um tanque natural na região central do Rio Grande do Norte. Contexto (Mossoró), 3: 176-193.

SANTOS JÚNIOR, V., ROCHA, L.C.M., OLIVEIRA, D.L., GONZAGA, S.P.F., ARAÚJO, M. R. 2015. Os vestígios arqueológicos e paleontológicos em tanques naturais das microrregiões de Angicos, oeste e Serra de Santana, Rio Grande do Norte, Brasil. Revista Tarairiú, 1 (10): 76-89.

SANTOS, M.F.C.F., BERGQVIST, L.P., LIMA-FILHO, F.P., PEREIRA, M.M.V. 2002. Feições tafonômicas observadas em fósseis pleistocênicos do Rio Grande do Norte. Revista de Geologia, 15: 31-41.

KRATIF, A. 1858. Uma excursão científica ao interior dessa província pelo Senhor 
J.L. Brunet. Diário de Pernambuco - A Carteira, 09 de maio de 1858, 01p.

LIMA, J.S., SILVA, J.L.L., SILVA, A.P.L., SARMENTO, J. 2013. Pesquisa paleontológica em depósito de tanque arenítico com mamíferos pleistocênicos, município de Delmiro Gouveia, AL. In: Congresso Brasileiro De Paleontologia, 23., 2013, Gramado. Anais... Gramado, SBP, p. 241-242.

LIMA, J.S., SILVA, J.L.L. 2016. Mamíferos fósseis pleistocênicos em tanque arenítico no município de Delmiro Gouveia, Alagoas, Brasil. Estudos Geoecológicos, 26(2): 77-90.

SILVA, D.G., CORRÊA, A.C.B., AMORIM, R.F. 2017. Caracterização morfológica e dinâmica ambiental das marmitas (weathering pit) no distrito de Fazenda Nova, Pernambuco - Nordeste do Brasil. Revista Brasileira de Geomorfologia, 18(2): 349-362.

SILVA, F.M. 2014. Tafonomia em tanque de Fazenda Nova, município de Brejo da Madre de Deus, Estado de Pernambuco, Nordeste do Brasil. Recife, 105p. Tese de Doutorado. Programa de Pósgraduação em Geociências, Instituto de Geologia. Universidade Federal de Pernambuco.

SILVA, J.L.L. 2008. Reconstrução paleoambiental baseada no estudo de mamíferos pleistocênicos de Maravilha e Poço das Trincheiras, Alagoas, Nordeste do Brasil. Recife, 213p. Tese de Doutorado. Programa de Pós-graduação em Geociências, Instituto de Geologia. Universidade Federal de Pernambuco.

SPIX, J.B.V., MARTIUS, K.F.P.V. 1824. Travels in Brazil in the years 1817-1820. London, A. \& R. Spottiswoode, 298p.
SPIX, J.B.V., MARTIUS, K.F.P.V. 1828. Reise in Brasilien in den Jahren 1817 bis 1820. München, I.J. Lentner, 468p.

SPIX, J.B.V., MARTIUS, K.F.P.V. 1968. Viagem pelo Brasil: 1817-1820. São Paulo, Edições Melhoramentos, 332p.

TEIXEIRA W., SABATÉ P., BARBOSA J.S.F., NOCE C.M., CARNEIRO M.J. 2000. Archean and paleoproterozoic tectonic evolution of the São Francisco Cráton. In: Cordani, U.G., Milani, E.J., Thomaz Filho, A. \& Campos, D.A. (Ed.). Tectonic evolution of South America. Rio de Janeiro, Sociedade Brasileira de Geologia, p. 101-138.

TWIDALE, C.R., CAMPBELL, E.M. 2005. Australian Landforms: Understanding a low, flat, arid and old landscape. Kenthurst, New South Wales, Rosenberg Publishing, 336p.

TWIDALE, C.R., VIDAL ROMANÍ, J.R. 2005. Landforms and geology of granitic terrains. Leiden, Balkema, 352p.

VIDAL ROMANÍ, J.R. 1989. Geomorfología granítica en Galícia (NW España). Cadernos do Laboratorio Xeolóxico de Laxe (Coruña), 13: 89-163.

VIDAL ROMANÍ J. R. 2008. Forms and structural fabric in granite rocks. Cadernos do Laboratorio Xeolóxico de Laxe, 33: 175-198.

VIDAL ROMANÍ, J.R., TWIDALE, C.R. 1998. Formas y paisajes graníticos. La Coruña, Universidad da Coruña Servicio de Publicaciones, 411p.

WALDHERR, F.R. 2018. Reconstituição paleogeomorfológica do Maciço do Itaóca e depósitos sedimentares de seu entorno, Campos dos Goytacazes (RJ). Rio de Janeiro, 160p. Dissertação de Mestrado. Programa de Pós-graduação em Geolo- 
gia, Faculdade de Geologia. Universidade do Estado do Rio de Janeiro.

WALDHERR, F.R., ARAÚJO-JÚNIOR, H.I., RODRIGUES, S.W.O. 2017a. Origem e morfologia de tanques naturais no Nordeste do Brasil. Pesquisas em Geociências, 44(3): 467-488.

WALDHERR, F.R., ARAÚJO-JÚNIOR, H.I., RODRIGUES, S.W.O., TUPINAMBÁ, M., VAZ, O.R. 2017 b. Tanques naturais: Considerações sobre origem e morfologia e descrição da primeira ocorrência fora do Nordeste do Brasil. In: Simpósio De Geologia Do Sudeste, 10., 2017, Diamantina. Anais... Diamantina, SBG.

WALDHERR, F.R., ARAÚJO-JÚNIOR, H.I., RODRIGUES, S.W.O., TUPINAMBÁ, M. 2018. A origem dos tanques naturais brasileiros: $\mathrm{O}$ modelo polifásico subedáfico. In: Simpósio $\mathrm{Na}$ cional De Geomorfologia, 12., 2018, Crato. Anais... Crato, UGB.

XIMENES, C.L. 2003. Proposta metodológica para um programa de microreservatórios alternativos de água nos sertões semi-áridos brasileiros, associado ao resgate de fósseis. Fortaleza, 146p. Dissertação de Mestrado. Programa de Pós-graduação em Geologia, Instituto de Geologia. Universidade Federal do Ceará.
XIMENES, C.L. 2006a. Novas ocorrências de fósseis de megafauna no neoquaternário do estado do Ceará, Brasil. In: PALEO NE 2006 - Reunião Anual Regional da Sociedade Bras. De Paleontologia,, 2006, Sobral (CE). Resumos, Sobral, UVA, p. 25.

XIMENES, C.L. 2006b. A área paleontológica quaternária de Itapipoca, Ceará. In: PALEO NE 2006 - Reunião Anual Regional da Sociedade Bras. De Paleontologia, 2006, Sobral (CE). Resumos, Sobral, UVA, p. 26.

XIMENES, C.L. 2009. Tanques fossilíferos de Itapipoca, CE: Bebedouros e cemitérios de megafauna pré-histórica. In: Winge, M., Schobbenhaus, C., Souza, C.R.G., Fernandes, A.C.S., BerbertBorn, M., Queiroz, E.T., Campos, D.A. (Ed.). Sítios Geológicos e Paleontológicos do Brasil: SIGEP - Comissão Brasileira de Sítios Geológicos e Paleobiológicos. Brasília, p. 465-478.

XIMENES, C.L., SANTOS, A.S.T. 2011. Itapipoca 1961: A expedição João Cativo e seu legado para a paleontologia brasileira. In: CARVALHO, I. (Ed.). Paleontologia: Cenários de Vida - Paleoclimas. Interciência, Rio de Janeiro, volume 5, p. 795-806. 